\title{
AGÊNCIA, GÊNERO E SEXUALIDADE DISSIDENTES NA ESCOLA: EXPERIÊNCIAS DE JOVENS E PROFESSORES/AS EM MATO GROSSO DO SUL
}

\author{
AGENCY, DISSIDENTS GENDER AND SEXUALITY AT SCHOOL: \\ EXPERIENCES OF YOUNG PEOPLE AND TEACHERS \\ IN MATO GROSSO DO SUL
}

\section{RESUMO}

O objetivo desse artigo é analisar as experiências positivas em relação a gênero e sexualidade dissidentes nas escolas de Mato Grosso do Sul. A metodologia utilizada foi a coleta de relatos de diferentes jovens e professores/as de instituições públicas e privadas por meio de um blog divulgado em atividades educativas e mídias sociais. Teoricamente as análises foram feitas a partir das teorias pós-críticas em educação. Mesmo em uma realidade demarcada pela heteronormatividade, os resultados apontam para as possibilidades de agência dos/as participantes em diferentes contextos escolares, especialmente em cidades do interior do estado.

Palavras-chaves: Escola. Agência. Gênero. Sexualidade. Dissidência.

\begin{abstract}
The objective of this article is to analyze positive experiences in relation to dissidents gender and sexualities in schools in Mato Grosso do Sul. The methodology used was the collection of reports from different young people and teachers from public and private institutions through a blog disseminated in educational activities and social media. Theoretically the analyses were made from the post-critical theories in education. Even in a reality demarcated by heteronormativity, the results point to the possibilities of agency of the participants in different school contexts, especially in cities of the interior of the state.
\end{abstract}

Keywords: School. Agency. Gender. Sexuality. Dissidence.

\footnotetext{
${ }^{1}$ Atualmente faz parte do Grupo Impróprias Grupo de Pesquisa em Gênero, Sexualidade e Diferenças (CNPq UFMS). Estudante do terceiro ano do Ensino Médio no Colégio Nova Escola Ensino Médio (2018 a 2020). e mail: fabriciopupo1206@ hotmail.com

2 Pós-Doutorado na Faculdade de Educação - FACED/UFMS, Professor do Bacharelado em Ciências SociaisUFMS. e - mail: tiago.duque@ufms.br
} 


\section{Debates Insubmissos}

Revista

\section{INTRODUÇÃO}

As questões de gênero e sexualidade enfrentam muitas barreiras em relação à sua discussão, principalmente no âmbito escolar. Os motivos são inúmeros, mas pode-se citar o fato de serem considerados historicamente temas controlados. O preconceito diante das vivências fora da heteronormatividade pode produzir o silenciamento dos/as jovens e dos/as professores/as diante das experiências vivenciadas nas escolas. Heteronormatividade é entendida aqui como um conjunto de disposições (discursos, valores, práticas) por meio das quais a heterossexualidade é instituída e vivenciada como única possibilidade natural e legítima de expressão (WARNER apud JUNQUEIRA, 2016). Um arsenal que regula não apenas a sexualidade, mas também o gênero. As disposições heteronormativas voltam-se a naturalizar, impor, sancionar, promover e legitimar uma única sequência de coerência entre sexo-gênerosexualidade. Por isso, o silenciamento de experiências dissidentes, mas esse silenciamento em nada significa "repressão", ou que essas questões não estejam presentes contidianamente no contexto das instituições escolares, mesmo das distantes dos grandes centros.

Segundo Michel Foucault, é ingênuo acreditar que somos sexualmente reprimidos, já que vivemos em uma sociedade que há mais de um século "fala prolixamente de seu próprio silêncio, obstina-se em detalhar o que não diz; denuncia os poderes que exerce e promete libertar das leis que a fazem funcionar” (2017, p.13). Assim, ele afirma que a sexualidade não é proibida, antes produzida e controlada pelos padrões impostos pela sociedade. Considerando os avanços nas discussões em torno do gênero, especialmente ao que se refere a "identidade de gênero", hoje, podemos atualizar essas reflexões foucaultianas apontando que, como já ocorre há algum tempo com a sexualidade, o gênero também tem sido associado ao privado, isto é, como algo que não se deve discutir publicamente, mas, como sabemos, o que se fala ou não sobre ele nada tem a ver com algo que não diz respeito ao público, mas, as insituições de ensino.

O discurso de que escola, gênero e sexualidade devem constituir instâncias separadas tem ganhando força. Reações como o Programa Escola sem Partido tem motivado a perseguição aos/às professores/as sob acusação de doutrinação política e ideológica. Ele surgiu em 2004, através da iniciativa do então procurador do Estado de São Paulo, Miguel Nagib, e tem efeitos 


\section{Revista \\ Debates Insubmissos}

ameaçadores junto a professores/as de todo o país, inclusive de Mato Grosso do Sul (MS). Busca-se criminalizar o trabalho docente em torno de temas como gênero e sexualidade. A iniciativa é entendida como uma reação a um suposto fenômeno de instrumentalização do ensino para fins político ideológicos, partidários e eleitorais, que em seu ponto de vista representam doutrinação e cerceamento da liberdade do estudante em aprender (JARCEM, 2020).

Não é casual que gênero e sexualidade façam parte dos temas que os/as defensores/as dessa iniciativa apontam como sendo os mais permeáveis à doutrinação ideológica, uma vez que a perseguição à esses temas constituiu um alinhamento às pautas da bancada religiosa representante de uma parte da população apoiadora de preceitos morais ligados a extrema direita. Por isto, esses não deveriam ser discutidos na escola.

O gênero e a sexualidade se constituem em um aspecto importante da formação dos sujeitos e dos grupos, exigindo atenção no contexto das políticas e dos programas educacionais (LOURO, 2017). Entende-se assim que é impossível separar a escola das questões de gênero e sexualidade. A necessidade do trabalho docente nessa temática é corroborada pelos Parâmetros Curriculares Nacionais (PCN's) ${ }^{3}$, que colocam esses temas como transversais e relevantes para a discussão nos estabelecimentos de ensino, bem como para o processo de intervenção pedagógica (BRASIL, 1997). Segundo Vanessa Leite, o sistema educacional, tomando-os como referências, se organiza "com o propósito de garantir respeito as diversidades culturais, a atuação da educação na construção da cidadania e tendo como ideal a crescente igualdade de direitos" (2018, p. 131).

Os PCN's legitimam o trabalho do/a professor/a com gênero e sexualidade para além da reprodução humana, com informações relacionadas ao contexto social em que é exercida ou ressignificada. Portanto, se admitirmos que a escola não apenas transmite conhecimentos, nem

\footnotetext{
${ }^{3}$ Os temas são: Ética (Respeito Mútuo, Justiça, Diálogo, Solidariedade), Orientação Sexual (Corpo: Matriz da sexualidade, relações de gênero, prevenções das doenças sexualmente Transmissíveis), Meio Ambiente(Os ciclos da natureza, sociedade e meio ambiente, manejo e conservação ambiental), Saúde (autocuidado, vida coletiva), Pluralidade Cultural (Pluralidade Cultural e a Vida das Crianças no Brasil, constituição da pluralidade cultural no Brasil, o Ser Humano como agente social e produtor de cultura, Pluralidade Cultural e Cidadania) e Trabalho e Consumo (Relações de Trabalho; Trabalho, Consumo, Meio Ambiente e Saúde; Consumo, Meios de Comunicação de Massas, Publicidade e Vendas; Direitos Humanos, Cidadania) (BRASIL, 1998).
} 


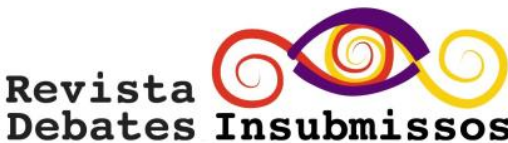

apenas produz, mas também fabrica sujeitos, então certamente encontramos justificativas não apenas para observar, mas especialmente, para tentar interferir na continuidade dessa prática de ressignificação (LOURO, 2016).

Contudo, o crescimento da visibilidade das diferentes orientações sexuais e identidades de gênero desestabiliza as instituições que tradicionalmente ajudaram a definir a regra e a norma moral em torno dessas experiências. Elas se dão via performances, isto é, via os vários atos de gênero, que "cria a ideia de gênero, e sem esses atos, não haveria gênero algum, pois não há nenhuma 'essência' que o gênero expresse ou exteriorize [...]" (BUTLER, 2003, p. 199). Isso ajuda a explicar a diversidade de marcas de gênero, independentemente dos sexos biológicos, encontrados entre os/as estudantes e entre os/as professores/as hoje em dia. O imperativo heterossexual possibilita certas identificações sexuadas e impede ou nega outras identificações (BUTLER, 2003).

A escola é um espaço onde é possível observar a emergência dessa visibilidade, assim como de conflitos em torno dessas experiências dissidentes de gênero e sexualidade que buscam afirmar formas de vida até então subjugadas. No entanto, também há experiências positivas em relação a valorização das diferenças de gênero e sexualidade na escola. Por isso, interessa-nos aqui analisar essas experiências avaliadas como positivas por jovens e professores/as em MS. A intenção foi priorizar os relatos avaliados pelos/as participantes como positivos para melhor compreender como se resiste a uma realidade preconceituosa, o que nos permitiu uma reflexão não somente sobre gênero e sexualidade, mas também sobre a agência dos/as participantes em relação a essa temática nas instituições escolares de diferentes contextos sul-mato-grossenses.

\section{METODOLOGIA}

Os dados em relação à violência e ao preconceito são alarmantes e remetem a discussão da segurança institucional, inclusive ambientes mais intimamente ligados a jovens dissidentes em termos de gênero e sexualidade, como a escola. Tal afirmação é verificada ao analisar os dados de 2016 da Associação Brasileira de Lésbicas, Gays, Bissexuais, Travestis, Transexuais 


\section{Revista \\ Debates Insubmissos}

(ABGLT) sobre jovens dissidentes de gênero e sexualidade em ambiente escolar, dos quais 60,2\% dos jovens se sentem inseguros em sua instituição educacional devido a sua orientação sexual e $42,8 \%$ pela forma como expressa seu gênero. O Brasil mantém um dos mais altos índices de matriz homofóbica, sem que isso suscite clamor público, não sem razão, o campo da educação tem sido apontado como um dos mais estratégicos (JUNQUEIRA, 2009).

Quando se trata de uma realidade mais específica, como a do estado de MS, as questões e dúvidas quanto a essas vivências disparam, uma vez que é um dos estados com menos estudos e índices sobre diversidade sexual no Brasil. Pouco se sabe sobre como MS lida com essas questões de gênero e sexualidade. Os poucos estudos que temos revelam, segundo pesquisas apontadas pelo Grupo Gay da Bahia de 2016, que MS, com uma população de aproximadamente 2.778.986 ${ }^{4}$ habitantes, é o $12^{\circ}$ estado do país mais violento em relação à população LGBT $^{5}$. Isso justifica este estudo, afinal, os resultados podem contribuir para a produção de atividades de enfrentamento a essa realidade de violência. Além disso, dados da pesquisa qualitativa nacional "Escola sem Homofobia", conduzida pela ONG Reprolatina (2011), indicam o despreparo das escolas para receber estudantes LGBT. Essa pesquisa foi realizada em onze estados brasileiros e MS não participou, o que fortalece ainda mais a necessidade de pesquisas como a que desenvolvemos e aqui publicizamos.

Outro dado importante é apontando pela pesquisa da Organizações das Nações Unidas para a Educação, a Ciência e a Cultura (UNESCO), que afirma que alguns/algumas professores/as reconhecem que existe preconceito e discriminação na escola, mas que estes/as só se dariam nas relações entre jovens, negando a vigência entre professores/as e estudantes. Mas, apesar do quadro mapeado de violências, preconceitos e discriminações envolver todos os sujeitos na escola, há subliminarmente vontade e ações contra esse cenário material e simbólico, mesmo entre muitos/as professores/as (UNESCO, 2004).

\footnotetext{
${ }^{4}$ Todos os dados em relação ao número de habitantes citados nesse artigo foram retirados do site do Instituto Brasileiro de Geografia e Estatística -IBGE.

${ }^{5}$ A sigla LGBT (Lésbicas, Gays, Bissexuais, Travestis e Transexuais) é usada aqui sem a pretensão de abarcar todas as categorias político identitárias presentes na contemporaneidade, ao contrário, reconhecemos sua ilimitada capacidade de comtemplar todas as experiências da diversidade sexual.
} 
Nesse sentido, é oportuno a abertura do debate e da visibilidade aos posicionamentos, dúvidas e questionamentos dos/as professores/as na busca por práticas, estratégias e ações que contribuam com um espaço escolar plural e democrático. É nosso interesse que essa discussão mais ampla, de projetos comprometidos com a transformação que considerem o papel do/a professor/a na produção das diferenças, seja considerada a partir das próprias condições de trabalho para a prática do combate à discriminação e a garantia de liberdade e segurança para todos/as.

Percebe-se que, historicamente, o processo de formação dos/as professores/as se voltou ao campo de disciplinas clássicas com o objetivo de adaptar os indivíduos às necessidades da sociedade, desconsiderando particularidades e processos culturais. A educação brasileira estrutura-se a partir de discursos que reverberam em conjunto dinâmico de valores e normas responsáveis por reduzir a figura do "outro", considerando estranho, pecador, pervertido ou criminoso todos aqueles/as que não se sintonizassem com a heteronormatividade (LOURO, 2017). Portanto, se torna compreensível pensarmos na instituição escolar como reguladora e disciplinar, pois é para isso que ela foi criada. Há uma pedagogia de gênero e sexualidade no espaço escolar que opera por meio da violência e da omissão, conformando um horizonte de expectativa aos/às estudantes sobre o que é ou não aceitável nos comportamentos sociais (BALIEIRO, RISK, 2014).

Levando em consideração essa discussão, essa pesquisa foi dividida em duas grandes fases, uma desenvolveu-se de maio de 2018 a maio de 2019, focada em jovens que estudaram ou estudam em MS, a outra, de maio de 2019 a maio de 2020, focada em professores/as que trabalharam ou trabalham em escolas neste estado. Cada uma dessas grandes fases teve etapas iguais no que se refere a questões metodológicas, sendo elas, para jovens e professores/as: $1^{\text {a }}$ levantamento bibliográfio, seja de gênero, sexualidade e jovens dissidentes de gênero ou gênero, sexualidade, educação e formação de professores/as; $2^{\mathrm{a}}$ - levantamento de dados de jovens e professores/as sobre as experiências positivas em relação a gênero e sexualidade dissidentes na escola, por meio do blog Transidentidades; $3^{\mathrm{a}}$ - análise desses dados deixados pelos/as jovens e, posteriormente, pelos/as professores/as no referido blog. 


\section{Revista \\ Debates Insubmissos}

O blog Transidentidades (www.transidentidades.com.br) foi desenvolvido como metodologia de pesquisa pelo autor principal desse estudo com o objetivo de recolher relatos de jovens e professores/as de MS sobre as experiências que nos interessou analisar. A participação na pesquisa se deu mediante ao preenchimento do formulário e aceite do termo de responsabilidade. A identidade dos/as participantes, como uma exigência ética, foi mantida em sigilo. Neste blog eles/as puderam contar suas experiências positivas no que diz respeito a gênero e sexualidade dissidentes vivenciadas exclusivamente na escola. Além disso, os relatos, desde que autorizados, foram tornados públicos no próprio blog, para que motivassem novas participações. Mas também foi possível os/as participantes deste estudo optarem por oferecer os relatos apenas para a pesquisa, sem que eles fossem publicados no blog.

Com as experiências de gênero e sexualidade dissidentes, pretendeu-se pensar a partir das "boas" experiências, sem, com isso, desconsiderar a realidade violenta em relação a essas vivências. Puderam participar dessa pesquisa jovens com idade entre 18 e 25 anos, que tiveram experiências dissidentes de gênero e sexualidade em alguma escola no estado de MS. O mesmo ocorreu com os/as professores/as, maiores de 18 anos, que atuam ou atuaram nas escolas do estado.

Os contatos iniciais com os/as participantes foram iniciados pela internet, através de páginas e perfis no Facebook e Instagram. O contato também foi feito através dos eventos onde o projeto foi apresentado ou discutido, tais como: Palestra "Empreender na Iniciação Científica", organizada por Júnior Achievement; reuniões do Impróprias - Grupo de Pesquisa em Gênero, Sexualidade e Diferenças; programa de "Extensão e Pesquisa" da Rádio Educativa UFMS; Intercom Centro-Oeste - mesa redonda "Desigualdade, Gênero e Comunicação"; etc.

Essa metodologia pareceu satisfatória para levantamento de dados sobre dissidências de gênero e sexualidade em instituições escolares em contextos sul-mato-grossense, em especial, em cidades de pequeno porte.

Na primeira fase, participaram da pesquisa 32 jovens, sendo 22 de escolas públicas e 10 de escolas privadas. Destes/as, 22 declararam de gênero feminino e 10 do masculino. O/a mais jovem declarou ter 18 anos, o/a mais velho/a 25 anos. Na capital Campo Grande, com 895.982 
habitantes estimados/as em 2019, foram 13 participantes, os/as demais são de cidades do interior. As demais cidades, o número estimado de habitantes e os/as participantes na primeira faze desta pesquisa, informamos a seguir: Jardim (26.097), Ponta Porã (92.526) com 03 cada; Coxim (33.543), Três Lagoas (121.388), Aquidauana (47.871) e Naviraí (54.878) com 02 cada; São Gabriel do Oeste (26.771), Porto Murtinho (17.131), Ladário (23.331), Nioaque (13.930) e Dourados (222.949) com 01 cada.

$\mathrm{Na}$ segunda fase, participaram 42 professores/as, sendo 27 de escolas públicas e 15 de escolas privadas. Destes/as, 28 declararam de gênero feminino e 14 do masculino. O/a mais jovem declarou ter 20 anos, o/a mais velho/a 60 anos. Na capital do estado, também foram 13 participantes, os/as demais são de cidades do interior. Informamos a seguir as cidades, citamos o número de habitantes previstos em 2019 para aquelas que não compuseram a primeira fase, assim como o número de participantes de todas elas: Coxim com 06; Três Lagoas com 05; Aquidauana com 04; Dourados e Ponta Porã com 03 cada; Terenos (21.806), Jardim e Pedro Gomes (7.674) com 02 cada; Ribas do Rio Pardo (24.615) e Alcinópolis (5.343) com 01 participante cada.

Essa metodologia, assim como o que se refere às análises dos dados, foi inspirada pela perspectiva pós-crítica em educação. A escolha por ela se justifica no sentido de que para essa perspectiva não existe um método previamente recomendado para a realização das investigações ou análises, principalmente porque se propõe a fazê-la a partir de questionamentos, dúvidas e problemas que são formulados diante da realidade a ser estudada. Trata-se de caminhos a percorrer, trajetos a realizar de forma que se tenha como base uma perspectiva, uma teoria. Assim, segundo Dagmar Estermann e Marlucy Alves Paraíso,

Entende-se metodologia como um certo modo de perguntar, de interrogar, de formular questões e de construir problemas de pesquisa que é articulado a um conjunto de procedimentos de coleta de informações, produção de informações e de estratégia de descrição e análise (2014, p.18).

A escolha pela perspectiva pós-crítica está relacionada principalmente com a possibilidade de conseguirmos dados sobre as práticas dos/as perticipantes no que se refere a agência diante da realidade já apresentada. Esse tipo de pesquisa é aberta, aceita diferentes traçados e é movida pelo desejo de pensar coisas diferentes (MEYER, PARAÍSO, 2014). 


\section{Debates Insubmissos}

Revista

\section{ANÁLISES}

\subsection{As experiências dos/as jovens}

A escola é um espaço muito importante para a socialização e faz parte do trabalho do/a professor/a garantir essa interação atendendo todas as representações (VENCATO, 2014). A jovem Sofia, 20 anos, de escola particular, apontando algo como positivo, afirmou que "os professores discutem e trabalham esses temas em sala de aula". Isso corrobora o quanto é importante tornar a discussão sobre gênero e sexualidade comum, cotidiana. Para isso é necessário criar o hábito de discutir a temática, incentivando um clima de respeito entre as diferentes representações (LOURO, 2017).

Aurora, 19 anos, de escola particular, por sua vez, conta que viveu "um namoro assumido com uma colega na escola”, o que aponta que, além de ambientes possíveis de discussão sobre esse tema, a escola também torna um lugar possível dessas vivências. A relação homossexual é vista como diferente e a escola age positivamente nessa questão quando permite que a relação seja vista. Segundo Guacira Lopes Louro (2017), um papel a ser desempenhado pela escola é exatamente esse de desestabilizar as "verdades únicas", os restritos modelos hegemônicos da sexualidade normal, mostrando o jogo de poder e de interesse envolvidos na interseccionalidade de sua construção e, depois, apresentar as várias possibilidades sexuais presentes no social e na política da vida humana, produzindo o modo como são significadas e como produzem seus efeitos sobre a existência das pessoas.

Pedro, 22 anos, de escola pública, relatou algo parecido, mas, no caso dele, explicou que não foi muito fácil contar para os/as colegas de escola sobre a sua sexualidade, mesmo sendo efeminado: "Disfarçava a voz, o jeito de falar... era dificil, mas eu tentava. Até que chegou um aluno novo em minha sala e logo foi se declarando gay. O meu grupo de amigos o recebeu de braços abertos”. O processo de ocultação da posição de dissidência em relação à matriz heterossexual, faz mais do que simplesmente regular a vida social de pessoas que se relacionam sexualmente com outras do mesmo gênero à medida que as submete ao segredo, ao silêncio as expõe ao desprezo público (JUNQUEIRA, 2016). Mas, Pedro conta-nos que a partir da chegada e, principalmente, da recepção desse novo estudante, tudo mudou: "Eu me vi nele e daí aos 
Revista

Debates Insubmissos

poucos fui me abrindo com meus colegas. Não preciso dizer quanto apoio recebi. Enfrentei preconceitos, claro! Colegas e piadinhas de alguns professores, mas tive apoio de outros". Segundo Rogério Junqueira (2015),

\begin{abstract}
Sair do armário implica uma gestão das fronteiras da (hetero)normalidade (na qual estamos todos/as envolvidos e pela qual somos afetados/as) e atua como um regime de controle de todo o dispositivo da sexualidade. Assim, reforçam-se as instituições e os valores heteronormativos e privilegia-se quem se mostra devidamente conformado à ordem heterossexista (JUNQUEIRA,2015, p. 228).
\end{abstract}

Gabriel, 18 anos, de escola pública, reforça esse tipo de experiências positivas afirmando que suas memórias em relação a sexualidade "aconteciam durante o ensino médio". Essas memórias indicam uma postura vista como positiva de não silenciamento dessas experiências no contexto escolar, principalmente no Ensino Médio. Ele explica o porquê avalia essas experiências como positivas: "pensando na construção da minha identidade sexual, o contato e o respeito às diferentes sexualidades, no Ensino Médio, foram fundamentais para minha aceitação como homossexual”. Rose, 24 anos, de escola pública, faz a mesma afirmação, mas compara com as dificuldades que vivia em sua casa: "A casa não era muito confortável para mim. Foi na escola, com meus amigos que eu reuni forças para me assumir".

A avaliação positiva dos/as jovens em relação a essas experiências não nos faz negar o silêncio diante da emergência de uma sexualidade diferente que torna os/as professores/as cúmplices da ridicularização e do insulto público de alguns/algumas jovens (MISKOLCI, 2014). Ainda, segundo Richard Miskolci,

A escola ensina a estranhar aqueles que manifestam interesses sexuais por colegas do mesmo sexo, portanto, tem papel ativo na transformação de sua diferença em algo que espera que os outros estudantes venham a identificar como incorreto, inaceitável e até mesmo desprezível (MISKOLCI ,2014, p.80).

Considerando isso, desvelar as estratégias desse discurso e fazer frente a elas tornou-se um imperativo na defesa da democracia, em prol do aprofundamento dos direitos sexuais e liberdade de pensamento (BALIEIRO, RISK, 2014). Esse aprofundamento tem relação direta com a realidade das pessoas trans (travestis e transexuais), afinal, em termos de evasão escolar, as experiências trans parecem ser as que mais se destacam. Por isso, José Francisco, 25 anos, de escola particular, relatou: "Na escola, no ensino médio pude usar o banheiro do gênero em que 


\section{Revista \\ Debates Insubmissos}

me identifico. Tudo isso foi importante, pois evita-se a evasão escolar e ocorre uma diminuição da disforia, possibilitando um melhor aproveitamento dos estudos, que foi o meu caso".

Em sua experiência escolar, assim como e de muitos/as jovens, o fato de poder frequentar o banheiro de acordo com sua identidade de gênero é a validação da aceitação por parte da escola dessa diferença. Seu relato apresenta a importância desse espaço arquitetônico binário de gênero. "Uma arquitetura que fabrica gêneros, enquanto, sob o pretexto da higiene pública, diz tratar simplesmente da gestão do nosso lixo orgânico" (PRECIADO, 2002, p.4). Assim, o banheiro funciona como construção dessa identidade. De acordo com Preciado, onde a arquitetura parece "ser apenas a serviço das necessidades mais básicas, portas e janelas, paredes e aberturas, que regulam o acesso e a procura, operam em silêncio e discretamente como uso efetivo de 'tecnologias de gênero"' (PRECIADO, 2002, p.1).

Outra referência importante de aceitação citada por José Francisco é o nome social e o conforto que ele pode gerar. Segundo ele, "Minha experiência positiva na escola se fez de algumas maneiras...tendo o nome social respeitado por todos funcionários, professores e coordenadores. O nome estava em listas, no armário, na chamada e afins". É compreensível o que o uso do nome social e do banheiro podem representar, quando nos deparamos com índices relacionados à violência sofrida pela população trans. De acordo com a Associação Nacional de Travestis e Transexuais - ANTRA, 90\% dos transgêneros dependem da prostituição para sobreviver (ANTRA, 2017). Guardando as devidas proporções, esses dados podem ser ampliados para outras experiências dissidentes de gênero e sexualidade, afinal, segundo Berenice Bento (2011), os indivíduos LGBT são submetidos a isolamento social, zombaria e agressões por parte de seus "colegas".

Em relação a Educação Infantil, os/as jovens também apresentaram dados relevantes quando de suas contribuições para esta pesquisa. Sofia, afirmou: "Na educação infantil e ensino fundamental tive contato com uma educação muito crítica, consciente e de inclusão...". A abordagem do assunto por parte dos/as professores/as já na Educação Infantil é potente, ainda que muitos/as professores/as, de diferentes níveis de ensino, movidos/as pela boa vontade e desejo de se engajar em práticas que combatem o preconceito relacionando à orientação sexual, não se 
sintam à vontade ou não se consideram portadores/as de conhecimento suficiente para abordá-los (BALIEIRO, RISK, 2014). Contudo, foi a experiência no final da Educação Básica que fez toda a diferença na vida de Sofia: "Então, quando eu fui para o ensino médio em um colégio maior, também particular, com muitos LGBT, eu não tive um grande estranhamento, nem quando descobri que eu mesma era lésbica”.

\subsection{As experiências dos/as professores/as}

A escola é um espaço importante para a socialização e a discussão, o/a professor/a tem papel fundamental nessa mediação. Por isso, "o principal desafio é passar por reconhecer e falar sobre as diferenças e entendê-las como um princípio estruturante da boa prática pedagógica, assim como deixar de lado a visão que ela só traz problema para o interior da escola". (VENCATO, 2014, p. 40). Nesse sentido, Rafael, 35 anos, de escola privada, informa que a primeira postura que ele tem é de verificar como jovens dissidentes de gênero e sexualidade são tratados pelos colegas, depois, tem uma atitude de acolhida: Quando percebo algum isolamento e outros indícios de sofrimento, procuro conversar com a pessoa e pedir autorização para falar com a coordenação e psicólogos. Ele, com os/as colegas de profissão, age da seguinte maneira: "Com os professores, procuro discutir sobre o tratamento aos homossexuais nos conselhos de classe".

Ao reconhecer a diferença no ambiente escolar, o/a professor/a encontra aí o seu desafio diário e, nesse momento, sua atitude pode ou não colaborar com a liberdade e o reconhecimento de diferentes representações de gênero e sexualidade nesse espaço. Por isso, Maria, 33 anos, de escola pública, assume que "A escola, como sendo um espaço social de formação humanizada, é o lócus para se estimular a liberdade entre os jovens". Considerando essa postura de alguns professores/as, parece-nos que a escola tem cumprido com o que Louro (2017) identificou como sendo um dos seus papéis:

Desestabilizar as 'verdades únicas', os restritos modelos hegemônicos da sexualidade normal, mostrando o jogo de poder e de interesses envolvidos na sua construção e depois, apresentar as várias possibilidades sexuais presentes no social e na política da vida humana, produzindo o modo como são significados e como produzem seus efeitos sobre a existência das pessoas (LOURO, 2017, p. 86). 


\section{Revista \\ Debates Insubmissos}

A proposição de estratégias pedagógicas, que busquem questionar e modificar as normas e valores heteronormativos no ambiente escolar, podem, antes de tudo, promover a reflexão do próprio docente diante da diferença e da invisibilidade da sexualidade dissidente. Segundo Larissa Pelúcio (2014),

Discutir relações de gênero, sexualidade e convívio com as diferenças é entrar no delicado terreno das intimidades, é mexer com moralidades, desestabilizar certezas, provocar incômodos que possam gerar insatisfação por parte de pais e dos próprios pares (PELÚCIO, 2014, p. 113).

Por isso, não é incomum que quando apareça, essa temática ela esteja vinculada a determinados esforços de controles por meio de grandes estratégias de saber e poder (FOUCAULT, 2017). Um exmeplo é quando "acabam por associar sexualidade à doença e ameaças coletivas, em especial, as experiências que não correspondem aos padrões normativos (BALIEIRO, RISK, 2014, p. 155). Marcelo, 28 anos, de escola privada, positivamente, não se refere diretamente a uma ameça: "Eu tento explicar que esse sentimento pelo mesmo sexo é normal”. Mas, na sequência, justifica: "porém cito a importância do uso de preservativos para evitar DST".

Aqui, não se trata de questionar a importância das orientações em relação à prevenção deste tipo de infeções/doenças, mas corre-se o risco de restringir a experiência da sexualidade a uma certa ameaça. Para evitar esse tipo de abordagem, um caminho é apostar na política pedagógica e curricular da identidade e da diferença. Segundo Tomaz Tadeu Silva (2009), essa política precisa "ir além das benevolentes declarações de boa vontade para com a diferença. Ela tem que colocar no seu centro uma teoria que permita não simplesmente reconhecer e celebrar a diferença e a identidade, mas questioná-la (SILVA, 2009, p. 100).

Os/as professores/as que participaram desta pesquisa se sentem despreparados/as para colocar em prática tal política. Ana, 42 anos, de escola pública, justificou esse despreparo pela complexidade do tema, apontando para os efeitos que isso pode ter: "Se não estivermos bem embasados cometemos o risco de reforçar o que tem sido posto há séculos”. Esmeralda, 23 anos, de escola privada, também se posiconou nesse sentido: "eu não me sinto preparada, apesar disso. Tanto pela questão de formação, quanto pelo preparo emocional que às vezes, 


\section{Revista \\ Debates Insubmissos}

precisamos oferecer aos alunos nesses momentos". Contudo, ela afirmou que se interessa pela temática e isso a faz buscar autores/as que podem ajudar, mas não acredita que isso possa acontecer com todos os/as professores/as.

Adriano, 33 anos, de escola particular, conta uma experiência vivida na sala dos/as professores/as que corrobora o que disse Esmeralda: "Na ocasião me manifestei dizendo que precisávamos acolher os jovens de novas turmas que estavam 'confusos', devido à sexualidade e as expectativas da família, escola e sociedade". Ele se colocou assim porque alguém tinha relatado sobre jovens estarem sofrendo perseguição de colegas e professores/as. Ele prossegue com o relato: "indaguei um colega, se ele já tinha vivenciado algo desse tipo. Após minha pergunta, a resposta foi: 'Sai fora, não fico prestando atenção em viado'”.

Esse cenário aponta para urgência de ações que promovam uma escola mais justa e que acima de tudo, garanta os direitos humanos, por exemplo a integração da Políticas Públicas, citadas nos PCNs (1997) para a orientação sexual. Contudo, a escola, ou pelo menos parte do corpo docente, parece desconhecer essas políticas, o que dificulta práticas e posturas que podem promover a ressignificação do espaço escolar para os jovens dissidentes. Alguns fatores podem estar relacionados ao despreparo desses/as professores/as como a falta de informação e formação em relação à gênero e sexualidade, que leva ao preconceito, ao silenciamento diante da violência e aceitação acrítica da heteronormatividade, afinal, "Não debater as convenções sociais que produzem formas de hierarquização impacta na própria relação que se constitui dentro dos muros da escola (BALIEIRO, RISK, 2014, p. 155).

Daqueles/as professores/as que desenvolvem o tema, no geral, não é de forma curricular, isto é, nestes termos, não entra como conteúdo formal (sistematizado, programado, a ser avaliado). Douglas, 35 anos, de escola pública, explicou o que outros/as participantes da pesquisa também relataram: "Essa temática aparece rotineiramente, mas não nos conteúdos e sim, por meio de bullying, manifestações de preconceito, conversas com os alunos em sala”. Diante dessa realidade, ele prossegue dizendo sobre sua postura: "As questões de gênero $e$ sexualidade são trabalhadas de maneira informal, durante momentos de conversa em sala de aula com exibição de vídeos e discussões. Dessa forma, trabalho o respeito entre as pessoas 
independente de suas diferenças". Mari, 34 anos, de escola privada, diante de uma realidade em que esses temas "só aparecem em reuniões da semana pedagógica", também atua como Douglas: "Sempre procuro entender o lado dos estudantes, ouvi-los, mas esses temas mesmo, só fora da sala de aula".

Assim, os dados apontam para um certo modo de atuação dos professores/as, e, consequentemente, para um tipo de aprendizado por meio de um currículo "oculto". Segundo Tomaz Tadeu da Silva, "na teorização crítica, a noção de um currículo oculto implica, na possibilidade de termos um momento de iluminação e lucidez, no qual identificamos uma determinada situação como constituindo uma instância de currículo oculto" (2017, p. 78-79). O que foi relatado por Douglas e Mari nos leva a essa compreensão. "A ideia é que uma análise baseada nesse conceito permite nos tornarmos conscientes de alguma coisa que até então estava oculta para nossa consciência" (2017, p. 78-79). Mas, por outro lado, essa linguagem restrita para se fazer referência a gênero e sexualidade não facilita que a diferença prolifere "no território do currículo", dificulta que "outros raciocínios, pensamentos, outras percepções sejam reconhecidas, autorizadas e ganhem espaço nos currículos escolares (PARAÍSO, 2018, p. 215).

\subsection{Agência e escola}

Como aponta Déborah Britzman, “a cultura da escola faz com que respostas estáveis sejam esperadas e que o ensino de fatos seja mais importante do que a compreensão de questões íntimas" (2018, p. 108). Essa interpretação da realidade escolar contextualiza o que os dados apresentados e analisados até aqui indicam. Contudo, as 74 pessoas que, nas duas fases, acessaram o blog e aceitaram participar da pesquisa apontam para outras possibilidades em relação a essa experiência cultural, não apenas para modos autoritários de interação social que, segundo a autora, "impedem a possibilidade de novas questões e não estimulam a curiosidade que possam levar estudantes e professores/as em direções que possam se mostrar surpreendentes" (2018, p. 108). Isso se torna possível por termos apostado que a possibilidade de olhar para as relações micro, como temos feito até aqui, nos permite destacar a capacidade de agência de jovens e professores/as no contexto da escola. 


\section{Revista \\ Debates Insubmissos}

Não se trata de negar que os currículos têm privilegiado noções particulares de gênero, a norma ainda insiste sobre como as identidades e diferenças são vistas. Os currículos escolares “produzem determinados tipos de sujeito, normalizando seus corpos e 'dizendo' o que é certo e o que é errado e quais comportamentos e características de gênero e sexualidade são aceitáveis ou não" (MEYER, SOARES, 2012, p. 47). Mas, como disse Sofia e outros/as jovens, os/as professores/as trabalham esse tema na sala de aula, mesmo que seja na perspectiva curricular não formal/oficial, quando se reconhece situações de bulling e preconceito, conforme nos contou o professor Douglas, ou apenas fora de sala de aula ou em "semanas pedagógicas", como disse Mari.

Mesmo existindo uma cultura com caracteríscas apontadas acima e uma produção curricular de corpos normalizados, é inegável que experiências de visibilidade em termos de dissidências de gênero e sexualidade são possíveis nos contextos sul-mato-grossense, afinal, os/as jovens Pedro, Gabriel, Aurora e Rose não só as viveram nas suas instituições escolares, mas reconheceram que as oportunidades ali oferecidas, a despeito do preconceito por parte de "colegas" e professores/as, foram positivas.

No caso de Rose, se comparada com o que vivia em casa, era muito melhor. Aurora relata, inclusive, que viveu um namoro "assumido" com outra jovem na escola.

Isso nos permite compreender a difereça, neste caso, no que se refere a gênero e sexualidade, não necessariamente resultando somente em desigualdade, pelo contrário, a diferença é entendida aqui como produzindo "formas democráticas de agência política" (BRAH, 2006, p. 374). A escola, assim, para aqueles/as com experiências de gênero e sexualidade dissidentes, torna-se o lugar possível para distintos agenciamentos, isto é, "a localização e o estabelecimento de conexões entre rotinas, hábitos e técnicas no interior de domínios específicos de ação e valor [...]” (ROSE, 2001, p. 51).

Essas conexões que indicam agenciamento também foram possíveis entre professores/as que relatam não apenas tratar desse tema junto aos/às estudantes, mas, também com seus/pares, é o caso de Rafael e Adriano. Mesmo que os “os domínios específicos de ações e valor” citados por Nikolas Rose (2001), em nosso caso, não facilite esse a abordagem sobre gênero e 


\section{Revista \\ Debates Insubmissos}

sexualidade, afinal, existe, como já nos referindos, tentativas de criminalização do trabalho docente no que se refere a isso, a discussão sobre essa temática acontece. Afinal, reconhecemos que

Os efeitos do discurso oposicionista às iniciativas de políticas educacionais na promoção da igualdade de gênero, no contexto nacional, foram a fomentação de medos e temores sociais em relação a mudanças nos padrões morais da sociedade, no que tange ao reconhecimento das desigualdades entre homens e mulheres, mas especialmente na abordagem escolar das formas dissidentes de experienciar gênero e sexualidade (BALIEIRO, DUQUE, 2018, p. 280).

Antes mesmo das proposições do "Programa Escola sem Partido" estarem em voga, a política educacional já estava demarcada por certos mecanismos de controle, afinal, apesar do ineditismo dos PCNs, e sua importância por ter sido "o primeiro documento oficial do MEC a associar a sexualidade à ideia de prazer" (JUNQUEIRA, 2009, p.182), precisamos levar em conta a crítica de que a menção à homossexualidade nele não é adequada, afinal,

[...] a noção de "orientação sexual" ali empregada e a tematização das doenças sexualmente transmissíveis, da Aids e da gravidez adolescente, aliadas a um discurso em torno da responsabilização dos sujeitos, não ensejaram o alargamento e o aprofundamento do debate em termos mais críticos, plurais e inovadores (JUNQUEIRA, 2009, p. 182).

Por isso, ao criticarmos posturas como a do professor Marcelo, que associa o tema da sexualidade dissidente a IST, não o fazemos na perspectiva de uma exclusiva responsabilização individualizada, antes, chamamos a atenção para o quanto as agências dos/as professores/as, assim como a dos/as jovens se dão no "interior de domínios específicos de ação e valor [...]" (ROSE, 2001) nos quais estão, historicamente, situados/as. As condições de trabalho dos/as professores/as aparecem aqui com uma, entre outras, limitações de atuação: mesmo com os PCNs existindo há décadas, falta formação didático-técnico-científica em gênero e sexualidade a ponto das professoras Ana e Esmeralda sentirem-se despreparadas diante da complexidade da temática.

Nos termos de Sherry Ortner (2007), a agência tem a ver com a intencionalidade e com o fato de se perseguir projetos, sempre culturalmente definidos. E, também, de forma entrelaçada, com o poder, com o fato de agir em contextos de relações de desigualdade, de assimetria e de forças sociais. Por isso, jovens e professores/as, no final das contas, não devem ser percebidos 
agindo simplesmente conforme a sua própria vontade e querer, a agência deve ser lida sempre como algo para além de quem age, constituída e constitutiva de um externo que independe do seu "querer".

Exatamente por isso, esse olhar sobre os agenciamentos em contextos escolares também deve servir para valorizar a agência que estudantes e professores/as desenvolvem em contextos escolares, especialmente diante desses temas e dessa experiência cultural tão normativa. Normatividade essa em disputa na contemporaneidade pelos/as defensores/as do Programa Escola sem Partido, que defendem que "a escola não deve abordar temas como política, religião, gênero e sexualidade, que professores/as em sua maioria são 'doutrinadores/as' e não são educadores/as, pois deveriam apenas se restringir a ensinar conteúdos técnicos" (SEVILLA E SEFFNER, 2017, p. 4-5).

Essa disputa está a Base Nacional Comum Curricular (BNCC), sucessora dos PCNs (1996). Promulgada em 2017, a BNCC, trouxe novamente para a discussão a garantia da abordagem gênero e sexualidade em sala de aula. Junto à discussão o documento levantou inúmeros debates, uma vez que se apontou a falta de participação de grupos de interesse que compõem o campo educacional, organizações da sociedade civil e representações acadêmicas que criticaram o documento por apresentar uma concepção reducionista de direito à educação. Além disso, ela também foi criticada por defensores do Programa Escola sem Partido e grupos religiosos de bancadas parlamentares porque, em um primeiro momento, incluia questão de gênero e sexualidade (FRIGOTTO, 2017; SILVA, BRANCALEONI e OLIVEIRA, 2019).

Antes de ser aprovado, o texto teve três diferentes versões e com a justificativa de que a temática de gênero provocara muita controvérsia e uma considerável exposição midiática, o Ministério da Educação (MEC) suprimiu os termos "gênero" e "orientação sexual", o que fortaleceu a ideia de que, como os temas não estão contemplados na Base, não podem ser trabalhados em sala de aula. Frases como 'Sai fora, não fico prestando atenção em viado'”, relatada pelo professor Adriano, acabam ganhando espaço nesse contexo de não oficialidade, logo, de não reconhecimento curricular das experiências dissidentes de gênero e sexualidade. 


\section{CONCLUSÕES}

Avaliamos que o nosso objetivo foi atingido, afinal, conseguimos analisar as experiências positivas de gênero e sexualidade dissidentes em MS. A metodologia demonstrou adequada, afinal foi possível acessar jovens e professores/as de diferentes instituições em várias cidades do estado, especialmente as interioranas. Assim, foi possível perceber as possibilidades de agenciamentos no contexto escolar, ainda que a heteronormatividade seja marcante na cultura escolar.

As experiências dos/as jovens mostram a importância da discussão sobre gênero e sexualidade tornar-se cotidiana na escola, assim como foi possível perceber o quanto a escola é um lugar possível para a vivência de experiências dissidentes em termos de gênero e sexualidade. A acolhida de jovens com esse perfil favorece o apoio para que se viva essas experiências de forma segura e não silenciada, especialmente durante o Ensino Médio. No entanto, a Educação Infantil também foi apontada como sendo um espaço para se formar criticamente para as diferenças. A problemática da evasão, especialmente de pessoas travestis e transexuais apareceu com a indicação da necessidade de se chamar as pessoas pelo nome que corresponda a sua identidade de gênero, assim como autorize o uso do banheiro por essa mesma identidade autoatribuída.

As experiências dos/as professores/as valorizam a postura de acolhida diante dos/as jovens dissidentes de gênero e sexualidade, o que deve ser demarcada pelo reconhecimento da diferença no ambiente escolar. A experiência positiva de se tratar desses temas não significa que eles não possam vir atrelados a discursos que podem os apresentar como uma possível ameaça quando, por exemplo, se associa experiências afetivo-sexuais dissidentes àsdoenças (IST). Ainda assim, existem professores/as buscando mais conhecimento para a abordagem do tema, pois não se sentem preparados/as para abordar a temática na perspectiva da política curricular da identidade e da diferença. Ainda sobre currículo, o que foi informado é que a temática não aparece de forma oficial, mas a partir de situações em que os/as professores/as identificam que precisam ser discutidas devido a própria vivência dos/as jovens. Alguns professores/as, inclusive, buscam 
pautar essa temática junto aos/às colegas, mas não necessariamente conseguem uma boa aceitação por parte deles/as.

Por fim, mesmo os PCNs propondo a abordagem da temática de modo transversal, a legislação parece insuficiente para garantir curricularmente a presença da temática na escola como ela deve ser ensinada. Por outro lado, a discussão em torno de uma nova legislação apresentou-se ainda mais frágil, afinal, foram retiradas da BNCC as referências a gênero e sexualidade. Contudo, ainda assim, a escola apresenta-se como um lugar possível para resistir às tentativas de criminalização do trabalho docente em torno do gênero e da sexualidade. Não se trata de minimizar os efeitos morais do Programa Escola sem Partido, antes, por mais que a agência tenha sido lida aqui como algo para além de quem age, buscou-se valorizar o agenciamento de jovens e professores/as em MS. Dito de um outro modo, por mais que ajam independentemente de um "querer", afinal, estão envoltos/as em relações de poder, há exemplos positivos que parecem tornar a diferença, em termos de gênero e sexualidade, uma experiência possível de ser reconhecida na escola.

\section{REFERÊNCIAS}

Associação Brasileira de Gays, Lésbicas, Travestis e Transexuais (ABGLT). As experiências de adolescentes e jovens lésbicas, gays, bissexuais, travestis e transexuais em nossos ambientes educacionais. Relatório da Secretaria de Educação da Associação de Lésbicas, Gays, Bissexuais, Travestis e Transexuais, 2016.

ABRAMOVAY, Miriam; CASTRO, Mary Garcia; SILVA, Lorena Bernadete da. Juventudes e sexualidade. Brasília: Unesco, 2004.

ASSOCIAÇÃO NACIONAL DE TRAVESTIS E TRANSEXUAIS (ANTRA). Mapa dos Assassinatos de Travestis e Transexuais no Brasil em 2017.

BALIEIRO, Fernando; RISK, Eduardo. Escola e Sexualidades: uma visão crítica à normalização. In: MISKOLCI, Richard; LEITE JÚNIOR, Jorge. (Orgs). Diferenças na educação, outros aprendizados. São Carlos: EdUFSCAR, 2014. p. 149-198. 
BALIEIRO, Fernado; DUQUE, Tiago. Notas sobre uma cruzada moral na era digital: a "Ideologia de Gênero"como uma ameaça à sociedade brasileira.In: El Desangriamento Latino Americano: Un panorama político contemporáneo y la reconfigurácion del estado neoliberal. Barranquilla: Corporácion Universitaria Americana, 2018. p. 278 - 311.

BELELI, Iara. Gênero. In MISKOLCI, Richard (Org.). Marcas da diferença no ensino escolar. São Carlos: Editora UFScar, 2014. p. 49-63.

BENTO, Berenice. Na escola se aprende que a diferença faz a diferença. Revista Estudos Feministas. 2011, vol.19, n.2, p. 549-559, 2011.

BRAH, Avtar. Diferença, Diversidade, Diferenciação. Cadernos Pagu, Campinas, n.26, p.329376, 2006.

BRASIL. Base Nacional Comum Curricular (BNCC). Segunda versão revista. Brasília, MEC/CONSED/UNDIME, 2016.

BRASIL. Ministério da Educação. Secretaria de Educação Fundamental. Parâmetros Curriculares Nacionais: pluralidade cultural, orientação sexual. Brasília: MEC/SEF, 1997.

BRITZMAN, Deborah. Curiosidade, currículo e sexualidade. In: LOURO, Guacira Lopes. (Org). O corpo educado: pedagogias da sexualidade. Belo Horizonte: Editora Autêntica, 2018. p. 83111.

BUTLER, Judith. Problemas de Gênero: a subversão da identidade. Rio de Janeiro: Editora Civilização Brasileira, 2003. 236 p.

FOUCAULT, Michel. A História da Sexualidade vol. I. São Paulo: Editora Paz e Terra, 2017. $175 \mathrm{p}$.

JARCEM, Pâmela da Silva. Do plano estadual de educação a "lei da mordaça": percurso e propostas do Programa Escola sem Partido para as políticas educacionais em Mato Grosso do Sul. 148f. Dissertação (Mestrado Profissional) - Educação - Universidade Estadual de Mato Grosso do Sul (UEMS), Campo Grande, 2020.

JUNQUEIRA, Rogério Diniz. Escola, Homofobia e Heteronormatividade. Revista Coletiva, Recife, n.18, s/p, jan/abr/2016.

JUNQUEIRA, Rogério Diniz. "Temos um problema em nossa escola: um garoto afeminado demais": Pedagogia do armário e currículo em ação. Revista Educação e Políticas em Debate, Uberlândia, n.2, v.4, p. 221-239, ago/dez, 2015.

JUNQUEIRA, Rogério Diniz. "Aqui não temos gays nem lésbicas": estratégias discursivas de agentes públicos ante medidas de promoção do reconhecimento da diversidade sexual nas escolas. 
Bagoas: revista de estudos gays, Natal, v.3, n.4, p.171-189, 2009.

LEITE, Vanessa. A política de educação no cenário recente da política sexual brasileira: venturas e desventuras dos "adolescentes LGBT" na relação com a escola. In: LOPES, Aline Casimiro; OLIVEIRA, Anna Luiza A. R. Martins, OLIVEIRA, Gustavo Gilson Souza. (Orgs) Os Gêneros da Escola: e o (im)possível silenciamento no currículo. Recife: Editora: UFPE, 2018. p. 127 162.

LOURO, Guacira Lopes. Um Corpo Estranho: ensaios sobre sexualidade e teoria queer. Belo Horizonte: Editora Autêntica, 2016. 92 p.

LOURO, Guacira Lopes . Corpo, Gênero e Sexualidade - Um debate contemporâneo na educação. Petrópolis: Editora Vozes, 2017. 189 p.

LOURO, Guacira Lopes. Gênero, sexualidade e educação - Uma perspectiva pósestruturalista. Petrópolis: Editora Vozes, 2017. 184 p.

MISKOLCI, Richard. Sexualidade e orientação sexual. In: MISKOLCI, Richard (Org.) Marcas da Diferença no ensino Escolar. São Carlos: Editora UFScar, 2014. p. 79-89.

ORTNER, Sherry. Poder e projetos: reflexões sobre a agência. GROSSI, Miriam et al. (Org.) Conferências e Diálogos: saberes e práticas antropológicas. Brasília: ABA/Nova Letra, 2007. p. $45-80$.

PARAIISO, Marlucy Alves. Metodologias de pesquisas pós-críticas em educação e currículo: trajetórias, pressupostos, procedimentos e estratégias analíticas. In: MEYER, Dagmar Estermann; PARAISO, Marlucy Alves (Orgs). Metodologias de pesquisas pós- críticas em educação. Belo Horizonte: Editora Mazza, 2014. p. 25-47.

PARAÍSO, Marlucy Alves. Currículo, gênero e heterotopias em tempo do Slogan "Ideologia de Gênero. In: LOPES, Aline Casimiro; OLIVEIRA, Anna Luiza A. R. Martins, OLIVEIRA, Gustavo Gilson Souza (Orgs) Os Gêneros da Escola: e o (im)possível silenciamento no currículo. Recife: Editora UFPE, 2018. p. 211-241.

PELÚCIO, Larissa. Gênero na escola. In: MISKOLCI, Richard; JÚNIOR LEITE, Jorge (Orgs) Diferenças na educação, outros aprendizados. São Carlos. EdUFSCAR, 2014. p. 106 - 119.

PRECIADO, Beatriz. Basura y Género, Mear/Cagar. Masculino/Femenino. Bilbao, Amasté, 2002.

REPROLATINA. Estudo qualitativo sobre homofobia no ambiente escolar em 11 capitais brasileiras. Projeto Escola sem Homofobia - componente de pesquisa, 2011.

ROSE, Nikolas. Como se deve fazer a história do Eu? Educação e Realidade, Porto Alegre, v. 
26, n. 1, p. 33-58, 2001.

SEVILA, Gabriela; SEFFNER, Fernando. A Guinada conservadora na educação: reflexões sobre o novo contexto político e suas reverberações para a abordagem de gênero e sexualidade na escola. Seminário Internacional Fazendo Gênero 11\& Women's Worlds Congress 13. Florianópolis, 2017.

SILVA, Caio Samuel Franciscati; BRANCALEONI, Ana Paula Leivar; OLIVEIRA, Rosemary Rodrigues. Base Nacional Comum Curricular e diversidade sexual e de gênero: (des)caracterizações. Revista Ibero-Americana de Estudos em Educação, Araraquara, v. 14, n. esp. 2, p. 1538-1555, jul. 2019.

SILVA, Tomaz Tadeu. A produção social da identidade e da diferença. In: SILVA, Tomaz Tadeu; HALL, Stuart; WOODWART, Kathryn (Orgs). Identidade e diferença: a perspectiva dos estudos culturais. Petrópolis: Editora Vozes, 2009. p. 73-102.

SILVA, Tomaz Tadeu. Documentos de Identidade: uma introdução às teorias do currículo. Belo Horizonte: Editora Autêntica, 2017. 153 p.

VENCATO, Ana Paula. Diferenças na escola. In: MISKOLCI, Richard; JÚNIOR LEITE, Jorge (Orgs.). Diferenças na educação, outros aprendizados. São Carlos: EdUFSCAR, 2014. p. 1956.

Submetido em: $28 / 05 / 2020$

Aprovado em: 28/07/2020 